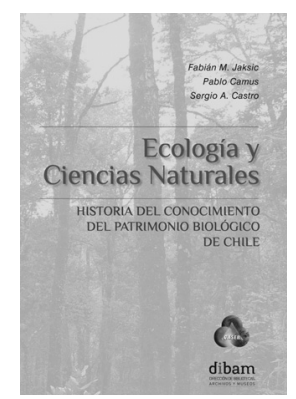

\title{
Fabián M. Jaksic, Pablo Camus y Sergio A. Castro. Ecología y Ciencias Naturales. Historia del conocimiento del patrimonio biológico de Chile
}

\author{
Santiago de Chile: Dirección de Bibliotecas, Archivos y \\ Museos, 2012. 228 p.
}

\author{
Rodrigo Torres Cañete ${ }^{1}$
}

\begin{abstract}
El estudio historiográfico de una ciencia bien puede consistir en una exposición pormenorizada de sus logros, narrados en función de situaciones, personajes y anécdotas atractivos, que suelen adquirir tanta celebridad como el avance o descubrimiento al que se refieren. Es por esta forma tradicional de hacer historia que resulta difícil disociar a Newton y la gravedad de las manzanas, o a Fleming y la penicilina del desorden de su laboratorio. Tratada así, la ciencia es percibida como un acervo creciente de explicaciones comprobadas que ha sido enriquecido por los buenos investigadores, pero que ha sido obstaculizado, en su crecimiento, por quienes son recordados como defensores de teorías o prácticas erradas. Se produce así una visión maniqueísta en que el descubridor se lleva los honores, frente a estudiosos incapaces de dar con la o las explicaciones correctas.
\end{abstract}

Una obra clave en la historia de la ciencia planteó, sin embargo, que esta no se desarrolla a través de la progresiva acumulación de descubrimientos e inventos individuales, sino que a través de procesos complejos que deben ser entendidos a la luz de las posibilidades de cada época y de las particularidades de cada comunidad de científicos, entre otros componentes. En consecuencia, propugnó un cambio historiográfico adecuado a esta nueva conceptualización: se debe dar cuenta de la

\footnotetext{
1 Magíster en Geografía y Geomática. Instituto de Geografía, Pontificia Universidad Católica de Chile (Chile). E-mail: rjtorres@uc.cl
}

integridad histórica de una ciencia en su propio tiempo, en vez de buscar contribuciones sucesivas a un acervo creciente. Ello implica revisar las prácticas científicas cotidianas, lo que de suyo las humaniza, intentando descifrar relaciones entre discípulos y maestros, diferencias de carácter, opinión e ideas, los contextos de avance técnico y las necesidades sociales, entre muchas otras categorías que dan tanto valor al acierto como al error.

El flamante libro de Fabián Jaksic, zoólogo; Pablo Camus, historiador, y Sergio Castro, botánico, se inserta en esta corriente renovada y presenta una historia de la ecología y de las ciencias naturales en Chile. No es una historia natural más, sino una narración de cómo esta se ha construido a partir de ciertas disciplinas. Es una metahistoria, elaborada con profundo respeto al trabajo constante desarrollado por investigadores e instituciones abnegados y apasionados de sus respectivos objetos de estudio, y que reciben, con este libro, un homenaje que por fin trasciende el reducido circuito académico en que sus nombres son reconocidos y admirados, al articular sus contribuciones con procesos históricos mayores.

Esta historia no comienza desde el principio, sino que desde fuera. Con el objetivo de incorporar este estudio en un contexto global, en que se conectan las Ciencias Naturales en Chile con los desarrollos internacionales, la obra se inicia con una breve perspectiva histórica del naturalismo y de los avances teóricos más influyentes para la ecología en su doble significación, como ciencia y como ideología. 
La revisión comienza en 1869, año en que es acuñado el concepto "ecología" por el biólogo alemán Ernst Haeckel, y que significó superar las prácticas eminentemente descriptivas que habían caracterizado a los estudios sobre la naturaleza. Luego retrocede cronológicamente a la propuesta taxonómica de Linneo y continúa con Kosmos de Von Humboldt, los estudios botánicos de la generación de Frederic Clements y Henry Allan Gleason, la Nueva Ecología orientada a las comunidades, la noción de ecosistema y su evolución desde Tansley a Lindeman, la Teoría del Nicho de George Evelyn Hutchinson, las perspectivas demográficas desde Volterra y Lotka, el concepto de biósfera, y el entendimiento de la Tierra como un ser vivo desde los tiempos míticos hasta las formulaciones de James Hutton, en 1785, y de James Lovelock, con su hipótesis de Gaia. Desde una perspectiva teórica, los autores suscriben la periodización propuesta por Donald Worster, quien considera que con las bombas de Hiroshima y Nagasaki surge una "era ecológica", pues, a partir de entonces, el ser humano adquiere conciencia de su potencial de acción planetaria y de la posibilidad técnica de la destrucción total. Sin embargo, la obra también se ocupa de los ecologismos, es decir, de las perspectivas políticas de la ecología, en un lapso mayor: desde el radical ensayo Walden, escrito por Henry David Thoreau en 1854, en adelante, hasta llegar a las ideas del filósofo noruego Arne Naess sobre la deep ecology.

A partir de este sintético pero bien provisto marco teórico, se desarrolla una historia de las Ciencias Naturales en Chile que comienza en la época de la Conquista. Los autores se ocupan de las pocas descripciones de la naturaleza que se conservan de los siglos XVI y XVII, y profundizan en la "Crónica y relación copiosa y verdadera de los Reinos de Chile", terminada en 1558 por Gerónimo de Bibar. Dicha obra tiene una clara inspiración geográfica, y presenta valiosas descripciones del territorio, anotaciones biológicas y observaciones relevantes sobre la morfología y distribución de varias especies vegetales. Enseguida se despliega un necesario recuento del aporte que distintos viajeros hicieron a la historia natural del país. Bien conocidas son las expediciones de personajes tan célebres como Feuillée, Graham, Pöeppig o Darwin, entre muchos otros, por lo que los autores se preocupan especialmente de sus descripciones territoriales y de sus contribuciones taxonómicas. Quien recibe más atención en este apartado, y con justos motivos, es el más célebre naturalista que haya nacido en territorio chileno, el abate Juan Ignacio Molina (1740-1829), aunque, en realidad, no se trata de un análisis biográfico convencional: más bien, la obra busca entender las percepciones que han tenido, sobre su figura, investigadores chilenos más recientes. Ello nos permite aquilatar su influencia en el desarrollo local de las Ciencias Naturales, que pudo ser escasa debido a que Molina desarrolló su carrera académica y científica en Bolonia, Italia, a causa de la Pragmática Sanción de 1767 que expulsó a los jesuitas de América. Sin embargo, los botánicos y zoólogos chilenos sí reconocen en Molina a un precursor, por medio de la valoración de su trabajo y del asombro frente a la innegable originalidad de sus planteamientos, que trascienden el naturalismo para insertarse en la vanguardia progresista de su época.

El tercer capítulo se intitula "Inserción de la naturaleza nacional en el ordenamiento científico global", aunque se trata, en realidad, de cómo se institucionalizaron las Ciencias Naturales en el joven Chile del siglo XIX. Comienza por retomar el ya aludido viaje de Darwin por Chile y, en lo que constituye una excepción para el texto, se expone este episodio a través de una historia muy apegada a cánones tradicionales, en que el relato se construye a partir de las impresiones del propio naturalista, y no de las huellas que este dejó en sabios chilenos de generaciones posteriores. A continuación se analiza in extenso la contribución de Claudio Gay a la creación de un imaginario geográfico nacional. Además de explicar su gran influencia en la zoología y la botánica local, se plantea cómo el sabio francés incorporó la naturaleza y la sociedad chilena en circuitos culturales y científicos de alcance mundial.

Desde aquí en adelante se desarrollan los aportes más cruciales de la obra de Jaksic, Camus y Castro, pues muestra a personajes conocidos de la historia de la ciencia nacional desde nuevas perspectivas, o arroja luz sobre investigadores cuya fama estaba relicta al reducido circuito académico y profesional de los naturalistas. 
Las bases de la práctica formal de las Ciencias Naturales en Chile se asocian al nombre de Rodulfo Amando Philippi (18081904), quien Ilegó a Chile a fines del año 1851, y a su hijo Federico. La variada documentación reunida sobre estos personajes no solo permite retratar a los grandes investigadores, sino que también a sujetos ideológicamente orientados y con una gran capacidad de gestionar, incluso más allá de lo institucional, las capacidades y financiamientos que son inherentes al desarrollo científico. En torno a estos sabios se articuló una notable generación de investigadores y docentes también extranjeros, quienes serían los responsables de educar a quienes conformarían, por primera vez, una comunidad científica auténticamente nacional. Entre ellos se destacaron Philibert Germain (1827-1913), entomólogo francés; Friedrich Johow (1841-1910) y Karl Reiche (1860-1929), botánicos alemanes; Edwyn Charles Reed (1841-1910), entomólogo británico, y el prolífico zoólogo francés Fernand Lataste (1847-1934), quien lideró la fundación de la Société Scientifique du Chili, en 1891. Con ellos, se amplió enormemente el conocimiento taxonómico y metodológico de sus respectivas disciplinas. Estos profesionales realizaron su labor al amparo de una visión política que fomentó la investigación de la naturaleza y la enseñanza de las Ciencias Naturales en los colegios, por lo que pudieron conformar sociedades, revistas científicas, museos y cátedras universitarias sobre naturalismo en las principales ciudades de Chile. De todo ello se brindan numerosos antecedentes, que permiten recrear la visión y las prácticas de este grupo de vanguardia.

Un tratamiento similar se da a la primera generación de naturalistas chilenos, articulada como una comunidad científica y que supo consolidar la institucionalidad heredada de los precursores extranjeros. Destacan aquí los nombres de Enrique Ernesto Gigoux, Guillermo Mann, Gualterio Looser, Carlos Muñoz Pizarro, Parmenio Yáñez y Nibaldo Bahamonde. Una mención especial merece Carlos Porter, fundador en 1897 de la Revista Chilena de Historia Natural, quien es destacado como el científico chileno más reconocido de fines del siglo XIX y principios del XX. La historia que se configura en este apartado es detallista, bien documentada y logra retratar cómo las diferentes ramas del naturalismo eclosio- naron durante este período, adquiriendo solidez en su práctica y divulgación disciplinaria.

En su quinto capítulo, los autores concentran sus esfuerzos en la evolución de las Ciencias Ecológicas en Chile, cuyo gran impulsor fue el profesor italiano Francesco di Castri, quien instaló la ecología científica moderna en el país. Esta sección del texto se articula en torno a dos ejes narrativos. El primero explica cómo esta disciplina se propagó a través de las distintas universidades y centros de estudio durante la segunda mitad del siglo XX, y cómo fue encauzada a través de distintas plataformas institucionales y financieras. El segundo considera a la ecología, o mejor dicho al ecologismo, en su dimensión política, y corresponde a una breve historia de personajes, sucesos, entidades y conflictos ambientales documentados para la centuria anterior, y que han preocupado a los naturalistas contemporáneos.

El libro cierra con un anexo sobre la historia de la Ecología en Chile preparado por el profesor Jaime Péfaur, quien junto a Ernst Hajek es uno de los más destacados discípulos de Francesco di Castri. En su primera parte complementa el relato del capítulo precedente con una visión proyectada desde los procesos ocurridos al interior de la Universidad de Chile. Muchos de los aspectos aquí tratados redundan sobre temas que ya habían sido abordados, pero el carácter vivencial de los testimonios valida su inclusión. En la segunda parte de este anexo, Péfaur realiza una narración autobiográfica respecto a su propia evolución como ecólogo, y lo hace en primera persona. De esta manera, se superponen tres escalas para explicar un mismo proceso: la de una historia general de la disciplina en Chile, la de una perspectiva institucional y la de una experiencia individual.

El libro que presentan los profesores Jaksic, Camus y Castro logra su propósito de reunir una cantidad relevante de noticias e informaciones históricas sobre las Ciencias Ecológicas en Chile, y consigue elaborar una propuesta historiográfica potencialmente replicable en otros casos de evolución disciplinaria. Son muchos los personajes, episodios e instituciones que son debidamente puestos en valor a lo largo del texto, que complementa la buena calidad de su investigación con valiosas fotografías e ilustraciones, y con un relato ameno y bien estructurado. 
